\title{
Splashing and Spitting Behaviour in the Combined Blown Steelmaking Converter
}

\author{
Matti Juhani LUOMALA, Timo Matti Juhani FABRITIUS, Esa Olavi VIRTANEN, Tero Petteri SIIVOLA and \\ Jouko Juhani HÄRKKI
}

Laboratory of Process Metallurgy, University of Oulu, PO Box 4300, FIN-90014, Finland. E-mail: matti.luomala@oulu.fi

(Received on January 21, 2002; accepted in final form on May 23, 2002)

\begin{abstract}
The amount of iron droplets ejected in the BOF affects on metallic yield, refactory wear and the progress of decarburisation. The purpose of this study was to investigate the effect of lance height, lance nozzle angle, lance position, top gas flow rate, bottom blowing and foamy slag on splashing and spitting. A new cold model method for investigating the effects of above-mentioned parameters on the location and quantity of liquid splashed on the walls of the model was utilised. According to the model tests, reduction of the nozzle angle increased the total amount of splashing and spitting considerably. Consequently, reduced productivity due to an increase in metal losses, skulling of the cone and converter mouth and further increased time for skull removal is expected. Introduction of bottom blowing increased splashing significantly on lower parts of the vessel. Lance position has an effect on total amount of splashing when bottom blowing is used. The presence of even minor foam layer on water surface reduced the amount of total splashing significantly.
\end{abstract}

KEY WORDS: BOF; steelmaking; splashing; spitting; physical model.

\section{Introduction}

In top and combined blowing processes oxygen is injected through multihole lance to the molten bath. The metal droplets are generated as a result of jet impact and the shearing action of the gas flow from the impact region when the jet strikes the metal surface and the gases are deflected upwards. ${ }^{1)}$ Molloy ${ }^{2}$ described the jet-liquid interaction in terms of three modes: dimpling, splashing and penetrating. The amount of iron droplets splashed into the gas and the slag influences metallic yield, refractory wear and the progress of decarburisation. ${ }^{3)}$ Chatterjee and Bradshaw ${ }^{3)}$ studied the effects of gas and liquid properties on the depth of depression and the critical depth, which marks the onset of splashing. They reported that splashing increased up to a certain jet momentum beyond which it decreased. Similar finding was also made by e.g. Standish and $\mathrm{He}^{4)}$ and Tanaka and Okane. ${ }^{5)}$ The direction of splashes is dependent on lance nozzle angle, lance height, profile of a jet cavity estimated from its depth and diameter ${ }^{5)}$ and overlap of the oxygen jets. ${ }^{6}$

Many researchers have modified the lance in order to affect splashing or spitting in the BOF. Sakai et al. ${ }^{6}$ developed a so-called low-spitting lance with alternated nozzle angles. Using quite similar lance to Sakai et al., Higuchi and Tago ${ }^{7)}$ emphasized the importance of proper design of nozzle diameters and inclination angles to give an optimum pressure distribution of the jet. Choi et al. ${ }^{8)}$ made modifications in order to reduce skull formation around the mouth of the vessel. Valentino et al..$^{9)}$ and Tabata et al. ${ }^{10)}$ reported the positive effect of wider lance angle on the amount of slopping in the BOF. Park and $\mathrm{Ha}^{11)}$ aimed to develop a nozzle design which would cause strong splashing and weak spitting.

Paul and Ghosh ${ }^{12)}$ studied splashing in both LD and QBOP but separately. They showed that the bottom blowing process is superior to top blowing, insofar as splashing and spitting are concerned. Actually, there are only a few model studies concerning splashing in the BOF during combined blowing. Standish and $\mathrm{He}^{4)}$ investigated drop production in combined blowing by measuring the total amount of droplets ejected outside of the model. A direct and an indirect effect of bottom blowing were described. Kitamura and Okohira $^{13)}$ studied behaviour of splash formation both in hot and in water model. For measuring the splashing rate, a special splash collector was inserted into the model. Meshalkin et al. ${ }^{14)}$ studied splash height in combined blowing using cold and hot models. According to their investigation, bottom blowing lowers the height of the splash. In their research, Garg and Peaslee ${ }^{15)}$ collected the splashed liquid in 67 plexiglass boxes which covered one-sixth of the model wall circumference. In the present paper, splashing on the walls and spitting through the mouth of the model are measured during top and combined blowing. The splashes are collected from the whole model wall circumference, so the splash distribution is easily obtained by one blow even if the interaction between lance jet cavities and bottom blowing plumes results irregular distribution. 
In order to clarify the interaction of the lance jet cavity with bottom blowing plume, experiments were first conducted with a very simple water model. ${ }^{16)}$ For the splashing studies in the BOF, more sophisticated model was developed. ${ }^{17)}$ In the present paper, the effect of lance height, lance nozzle angle, top gas flow rate, bottom blowing and foamy slag on the amount and direction of the splashing is investigated. Furthermore, the effect of various blowing parameters on the wear of refractory lining, on metal losses and on skulling of the cone is discussed.

\section{Experimental Set-up}

To simulate splashing in the steelmaking converter, three-dimensional water model apparatus was set up and scaled down to the $1: 9$ of the actual process. The cylindrical vessel was made of an acrylic glass and has an inner diameter of $487 \mathrm{~mm}$ and a height of $809 \mathrm{~mm}$. The geometrical and operational parameters for both the model and the converter are summarized in Table 1. A more detailed description of the apparatus is given elsewhere. ${ }^{17)}$

Special feature of the model was that the wall is perforated; altogether 60 holes in four rows around the wall. When all the parameters were set for the test compressed air was blown through the lance to splash the liquid. Splashed water then fell to the certain hole and was further guided through the tube into a corresponding bottle where water gradually accumulated during the blow. The rate of splash was measured by weighing the amount of liquid collected during the blow in each of the 60 bottles. The weight was divided by blowing time and area of corresponding hole.

The model lance tip was made of stainless steel. Converging-diverging or de Laval nozzles were used for blowing air; their specifications are given in Table 1 .

A collectible textile was used at the mouth of the model in order to estimate the amount of liquid ejected outside. The weight of the water obtained from the textile will be referred to as the amount of spitting in this paper.

\section{Modelling Considerations}

The dynamic similarity between the model and the actual converter was considered for both lance and bottom blowing by using several dimensionless numbers. All the symbols and their meanings are given in the Table 2.

\subsection{Lance Blowing}

Following dimensionless numbers were considered for the lance blowing:

$$
\begin{aligned}
& W e=\frac{\rho_{\mathrm{g}} u^{2}}{\left(\rho_{1} g \sigma_{1}\right)^{1 / 2}}=\frac{2 p_{x}}{\left(\rho_{1} g \sigma_{1}\right)^{1 / 2}} \\
& M m=\frac{\rho_{\mathrm{g}} u^{2} d_{0}^{2}}{\rho_{1} g h_{\mathrm{a}}^{3}} \\
& F r=\frac{u^{2}}{g \cdot H} \frac{\rho_{\mathrm{g}}}{\rho_{1}}=\frac{2 p_{x}}{\rho_{1} g H}
\end{aligned}
$$

\begin{tabular}{|c|c|c|}
\hline & BOF & Model \\
\hline Diameter of the vessel, $\mathrm{mm}$ & 4300 & 487 \\
\hline Height of the vessel, mm & 7200 & 809 \\
\hline Height of the bath, $m$ & 1.5 & 0.16 \\
\hline Charge weight, $\mathrm{kg}$ & $120 \cdot 10^{3}$ & 24 \\
\hline Lance height, $\mathrm{m}$ & $1.5-2.0$ & $0.16-0.22$ \\
\hline Number of nozzles & 5 & 5 \\
\hline Diameter of lance throat, $\mathrm{m}$ & 0.029 & 0.0016 \\
\hline Diameter of lance outlet, $\mathrm{m}$ & 0.040 & 0.00185 \\
\hline Nozzle angle, ${ }^{\circ}$ & 15 & 15 \\
\hline Gas supply pressure, bar & 10 & 5 \\
\hline Gas flowrate, $\mathrm{Nm}^{3} / \mathrm{min}$ & 340 & 0.6 \\
\hline Atmospheric pressure, $\mathrm{Pa}$ & 101325 & 101325 \\
\hline Gas density, $\mathrm{kg} / \mathrm{m}^{3}$ & 1.429 & 1.239 \\
\hline Liquid density, $\mathrm{kg} / \mathrm{m}^{3}$ & 7000 & 1000 \\
\hline Diameter of bottom nozzles, $\mathrm{m}$ & 0.004 & 0.001 \\
\hline Bottom gas flowrate, $\mathrm{Nm}^{3} / \mathrm{min}$ & $1.5-3.0$ & $0.025-0.05$ \\
\hline
\end{tabular}

The Weber number expresses the ratio of the momentum
Table 1. The geometrical and operational parameters.

Table 2. List of symbols.

\begin{tabular}{|ll|}
\hline$D_{t}$ & Diameter of the nozzle throat, $\mathrm{m}$ \\
$d_{0}$ & diameter of the nozzle exit, $\mathrm{m}$ \\
$E_{k}$ & specific kinetic energy, W/kg \\
$E_{b}$ & specific buoyancy energy, W/kg \\
$F r$ & the Froude number, - \\
$g$ & acceleration due to gravity, $\mathrm{m} / \mathrm{s}^{2}$ \\
$H$ & lance height, $\mathrm{m}$ \\
$H_{b}$ & height of the liquid bath, $\mathrm{m}$ \\
$m_{b}$ & weight of the liquid bath, $\mathrm{kg}$ \\
$m_{t}$ & total momentum flow rate, $\mathrm{N}$ \\
$M_{h}$ & dimensionless momentum flow rate, - \\
$M m$ & the momentum number, - \\
$n$ & number of nozzles \\
$p_{0}$ & supply pressure, Pa \\
$p_{a}$ & ambient pressure, Pa \\
$p_{x}$ & dynamic impact pressure at the surface, $\mathrm{Pa}$ \\
$Q$ & gas flowrate, $\mathrm{m}^{3} / \mathrm{s}$ \\
$u_{0}$ & gas velocity in the tuyere, $\mathrm{m} / \mathrm{s}$ \\
$u$ & gas velocity, $\mathrm{m} / \mathrm{s}$ \\
$u_{x}$ & gas velocity at the bath surface, $\mathrm{m} / \mathrm{s}$ \\
$W e$ & the Weber number, - \\
$x$ & cavity depth, $\mathrm{m}$ \\
$\alpha$ & nozzle angle \\
$\rho$ & density, $\mathrm{kg} / \mathrm{m}^{3}$ \\
$\sigma$ & surface tension, $\mathrm{N} / \mathrm{m}$ \\
\hline
\end{tabular}

intensity to the main liquid properties. ${ }^{18,1)}$ The momentum number $(\mathrm{Mm})$ is defined as the ratio between the jet momentum flow rate at different distances with the action of gravity on the same bath. ${ }^{19)}$ The Froude number represents the ratio between the inertial forces to gravitational forces. $^{20)}$

The dynamic impact pressure of the jet on the metal surface is defined ${ }^{1)}$

$$
p_{x}=1 / 2 \rho_{\mathrm{g}} u_{x}^{2}=\rho_{1} g x .
$$

According to Koria and Lange, the lance cavity depth $(x)$ can be obtained from Eqs. (5)-(7)

$$
\frac{x}{H}=4.469 \cdot \dot{M}_{\mathrm{h}}^{0.66}
$$

Dimensionless momentum flow rate $\dot{M}_{\mathrm{h}}$ is defined by:

$$
\dot{M}_{\mathrm{h}}=\frac{\dot{m}_{\mathrm{t}} \cos \alpha}{n \rho_{1} g H^{3}}
$$

The total momentum flow rate is given by: ${ }^{22)}$

$$
\dot{m}_{\mathrm{t}}=0.7854 \cdot 10^{5} n d_{\mathrm{t}}^{2} p_{\mathrm{a}}\left(1.27 \frac{p_{0}}{p_{\mathrm{a}}}-1\right)
$$


Table 3. Comparison between dimensionless numbers in actual BOF and physical model.

\begin{tabular}{|l|c|c|}
\hline & BOF & Model \\
\hline Froude number, - & $0.11-0.20$ & $0.43-0.80$ \\
\hline Momentum number, - & $(1.5-3.6) \cdot 10^{-3}$ & $(5.5-14.2) \cdot 10^{-3}$ \\
\hline Weber number, - & $230-305$ & $172-235$ \\
\hline
\end{tabular}

Table 4. Dimensionless numbers in BOF and physical model.

\begin{tabular}{|l|c|c|}
\hline & BOF & Model \\
\hline $\begin{array}{l}\text { Gas flow rate/nozzle, } \\
\mathrm{Nm}^{3} / \mathrm{min}\end{array}$ & $0.3-0.6$ & $0.005-0.01$ \\
\hline Froude number, - & $2.2-8.8$ & $8.9-35.6$ \\
\hline Kinetic energy, W/kg & $0.024-0.189$ & $0.121-0.970$ \\
\hline Buoancy energy, W/kg & $(2.9-5.8) \cdot 10^{-7}$ & $(5.3-10.7) \cdot 10^{-7}$ \\
\hline
\end{tabular}

Table 3 shows a comparison of the dimensionless numbers between the physical model and the BOF. According to $\mathrm{He}$ and Standish, ${ }^{18)}$ the Weber number is the most significant as the similarity criteria. The values of the Weber number in the present study are of same magnitude as in the BOF. Since water was chosen to describe molten metal in the model, increasing the momentum is the simplest method to reach more accurate similarity as far as Weber number is considered. However, the momentum number would get increasingly high values in the model. The effect of excessive momentum in the model is also seen in the too high values of Froude number. Nevertheless, the difference between the model and the actual process is not unreasonable.

\subsection{Bottom Blowing}

In the gas-stirred system, the fluid flow and mixing of the bath are caused by momentum transfer between blown gas and liquid. ${ }^{23)}$ Bottom gas flow rate in the model can be determined by the modified Froude number or by the mixing energy which is the sum of the kinetic energy and the buoyancy energy of the injected gas. ${ }^{24)}$ The following respective equations are given: $:^{23,25}$

$$
\begin{gathered}
F r=\frac{\rho_{\mathrm{g}}}{\rho_{\mathrm{l}}} \frac{u_{0}^{2}}{g H_{\mathrm{b}}} \ldots \ldots \ldots \ldots \ldots \ldots \ldots \ldots \ldots \ldots \\
E_{\mathrm{k}}=\frac{1 / 2 \rho_{\mathrm{g}} u_{0}^{2} Q}{m_{\mathrm{b}}} \ldots \ldots \ldots \ldots \ldots \\
E_{\mathrm{b}}=\frac{2 Q p_{\mathrm{a}} \ln \left(\frac{p_{\mathrm{a}}+\rho_{1} g H_{\mathrm{b}}}{p_{\mathrm{a}}}\right)}{m_{\mathrm{b}}}
\end{gathered}
$$

Table 4 presents that an adequate dynamic similarity is achieved when bottom gas flow rate of $5 \mathrm{l} / \mathrm{min}$ per nozzle is applied. The bottom gas flow rate of $10 \mathrm{l} / \mathrm{min}$ in the present study is too high compared to the real process but since the bottom blowing clearly has an influence on the amount and direction of liquid splashed, such high gas flow rate was also tested.

\section{Experimental Results}

Two lance positions in accordance with Fig. 1 were tested. In the first case, one nozzle (LP1) and in the other case

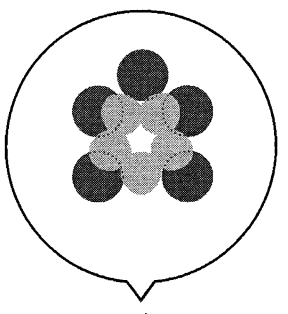

a)

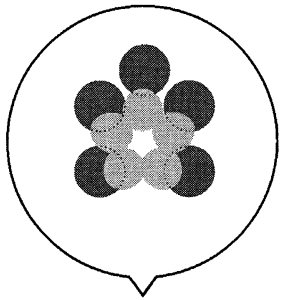

b)
Fig. 1. Lance positions under study a) LP1 and b) LP2.

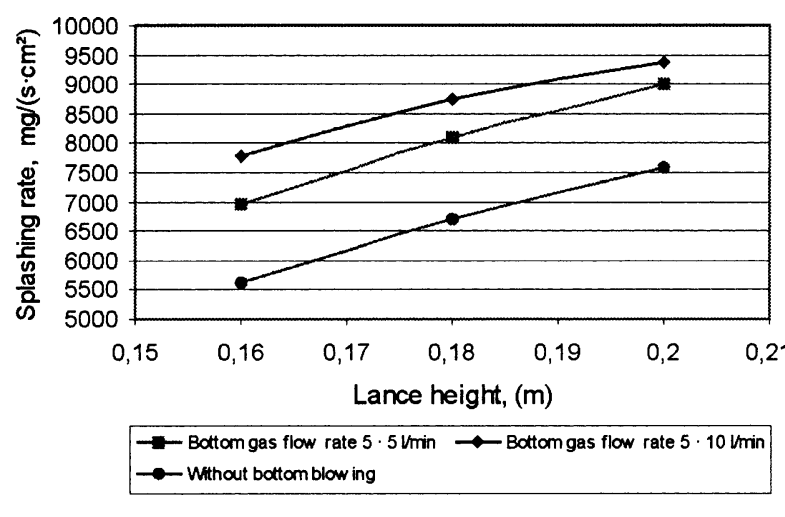

Fig. 2. Total splashing rate as a function of lance height with various bottom blowing gas flow rates.

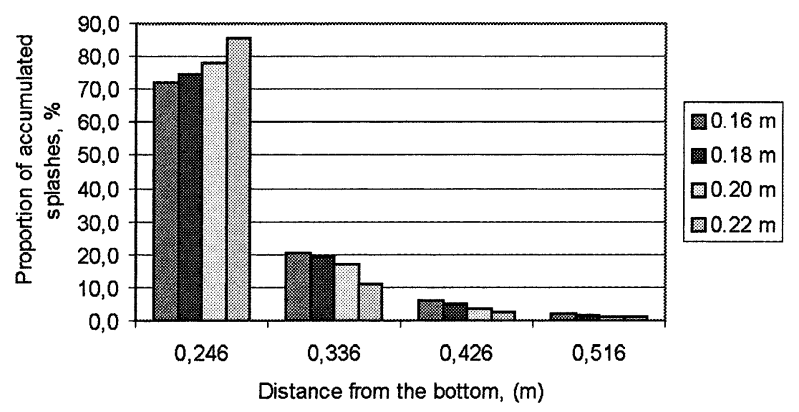

Fig. 3. The effect of lance height on proportion of splashes collected from different distances from the bottom.

two nozzles (LP2) are directed towards the taphole. Grey circles describe lance cavities whereas black circles describe bottom blowing plumes, i.e. an arrangement of five bottom plugs was used. In this paper, $5 \cdot 5 \mathrm{l} / \mathrm{min}$ (or $5 \cdot 10$ $\mathrm{l} / \mathrm{min}$ ) means that 5 (or 10) $\mathrm{l} / \mathrm{min}$ was injected through each of the five bottom plugs shown in Fig. 1.

\subsection{Lance Height and Gas Flow Rate}

According to Chatterjee and Bradshaw, ${ }^{3)}$ an increase in jet momentum or a decrease in lance height results in an increase in the total volume of liquid splashed beyond which it decreases. Similar behaviour was also observed in the present study. However, most of the tests were done at lance heights of $0.16-0.20 \mathrm{~m}$ where the reduction of lance height decreases the splashing rate as shown in Fig. 2.

As the lance is raised, the shape of the jet cavity becomes flatter and therefore greater share of the splashes is directed to the lower trajectories which is shown in Fig. 3. Additionally, model experiments reveal that when the current bottom plug arrangement is used, the taphole area exposes to severe splashing regardless of lance position or bottom gas flow rate. Above mentioned is observed for ex- 


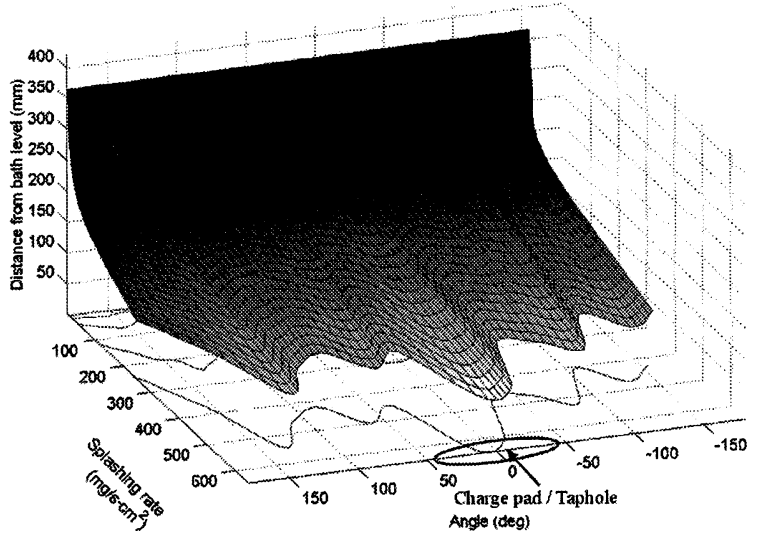

Fig. 4. Splashing rate on the wall circumference at lance height $0.20 \mathrm{~m}$ with bottom blowing $5 \cdot 5 \mathrm{Nl} / \mathrm{min}$ (LP1).

ample in Fig. 4 where LP1 was used at the lance height 0.2 $\mathrm{m}$.

When no bottom blowing was used at the lance height of $0.18 \mathrm{~m}$, reduction of top gas flow rate from 590 to 500 $\mathrm{Nm}^{3} /$ min decreased the total amount of splashing by $20.6 \%$ and spitting by $44.5 \%$. When bottom blowing $(5 \cdot 5 \mathrm{l} / \mathrm{min})$ was applied, splashing and spitting decreased by $22.5 \%$ by $56.2 \%$, respectively.

\subsection{Lance Nozzle Angle}

Experiments conducted with nozzle angle of $12^{\circ}$ show that the distribution of splashes on the wall is smoother than in the case of nozzle angle of $15^{\circ}$, i.e. peaks are not quite so distinctively seen. Furthermore, depending on the lance height the total amount of splashing is increased from 2.3 to $15.7 \%$. Compared to nozzle angle of $15^{\circ}$, spitting is increased substantially by $60.5 \%$ (lance height $0.18 \mathrm{~m}$, no bottom blowing).

\subsection{Bottom Blowing and Lance Position}

Introduction of bottom blowing increases splashing significantly, as can be seen in Fig 2. This result is equivalent to the findings of Standish and He. ${ }^{4)} \mathrm{LP} 1$ produces more severe areas of local stress as well as slightly greater total splashing than LP2. However, splashing on taphole and knuckle areas is lesser compared to LP2. Furthermore, when using bottom gas flow rate $10 \mathrm{l} / \mathrm{min}$, the splashing is particular high on areas of $0^{\circ}$ and $\pm 130^{\circ}$ (LP1) and on areas of $0^{\circ}, \pm 100^{\circ}$ and $180^{\circ}$ (LP2). With LP2, coalescence of the two gas jets, which are towards the taphole results one wider peak, thus heavier splashing on the taphole area.

\subsection{Foamy Slag}

Foam in the model was produced by an ordinary commercial liquid soap. The purpose of these tests was only to estimate the influence of foamy slag on the amount of liquid splashed compared to the other parameters. The presence of even minor foam layer on water surface reduced the amount of total splashing significantly. As the intensity of foaming is increased, splashing reduced particularly on lower knuckle and tapping areas and was almost eliminated on the rest of the walls.

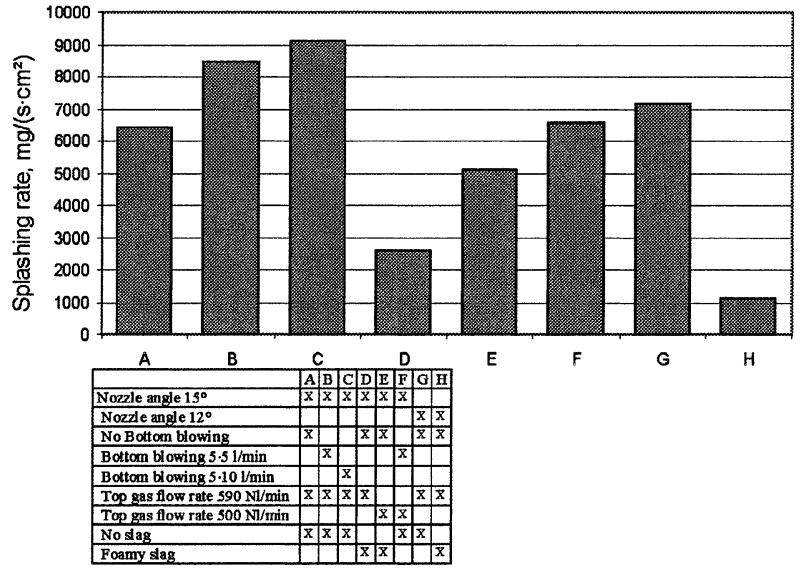

Fig. 5. The effect of different parameters on total splashing rate with lance height of $0.18 \mathrm{~m}$.

\section{Discussion}

\subsection{The Wear of the Refractory Lining}

Figure 5 depicts the influence of different blowing parameters on total splashing on the walls. As can be seen, introducing bottom blowing or decreasing the angle of inclination will increase the rate of splashing. Foaming slag and decreasing top gas flow rate have an inverse effect.

Increasing bottom gas flow rate changes the shape of the bottom of the jet cavity flatter which directs the splashes to the lower trajectory and consequently reduces spitting. Standish and $\mathrm{He}^{4)}$ presented that the bottom blowing influences on droplet generation by a direct and by an indirect effect. According to the model tests, splashing was $2.3-15.7 \%$ higher when nozzle angle was $12^{\circ}$. Furthermore, the area of heaviest splashing moved a little bit higher. The change was not as visible as Keilman et al. ${ }^{26)}$ reported in their experiments.

Foaming of slag reduced the values of measured splashing considerably. Reduction in the surface tension of water increases the amount of drops but the foam layer retards their course in the foam. Consequently, the lining wear due to the splashing is negligible during the (decarburisation) main blow period.

\subsection{Metal Losses}

Because of the losses of hot metal and other raw materials it is important to minimise the generation of dust in the BOF. Main mechanisms of dust formation are ejection of metal and slag droplets, entrainment of charged material and vaporisation. ${ }^{27)}$ Reduction of lance nozzle angle from $15^{\circ}$ to $12^{\circ}$ increases spitting as much as $61 \%$. Our finding is in agreement with those of Sakai et al. ${ }^{6)}$ and Higuchi and Tago. ${ }^{7)}$ Generally spitting is decreased as the lance height is increased. Bottom blowing decreases spitting considerably (28-51\%) depending on the intensity of gas flow rate. It is also evident that lower top gas flow rate and the presence of a foaming slag, reduces the rate of spitting as can be seen in Fig. 6.

\subsection{Skulling of the Cone}

The effect of various blowing parameters on skulling of the cone and formation of converter mouth build-up was estimated by examining both spitting and splashing on the top 


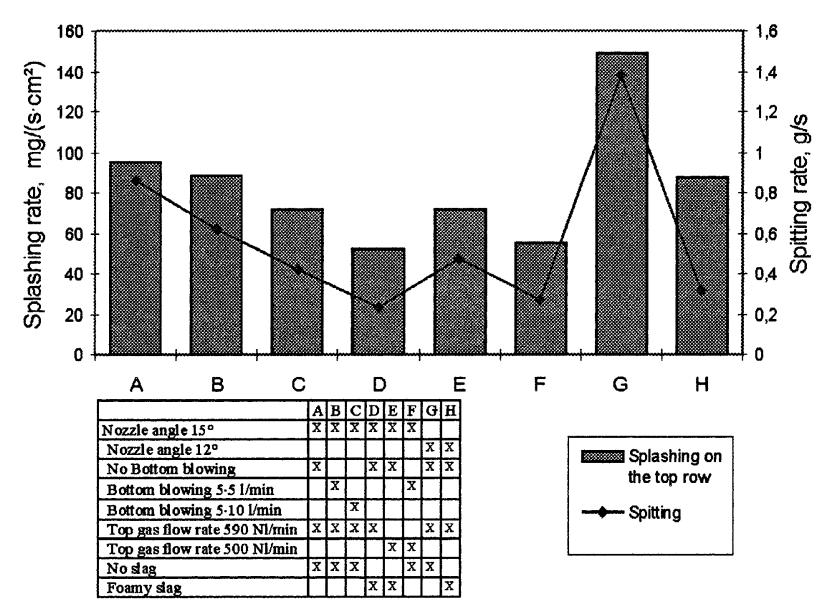

Fig. 6. The effect of different parameters on the amount of spitting and splashing on the top row.

row, Fig. 6. Increasing bottom gas flow rate decreases both spitting and splashing on the upper part of model which should also reduce the skulling of the converter cone area. However, according to Bock et al., ${ }^{28)}$ the bottom stirring should be kept to a minimum in order to prevent the $\mathrm{FeO}$ that has been formed during the early period of the blow from being reduced again. Excessive bottom stirring gas rate prevents the formation of a liquid slag. Consequently, non-liquid or highly viscous slag leads to e.g. lance skulling, upper converter cone, converter mouth and gas hood skulling as well as poor desulphurization and dephosphorization and lower yield. ${ }^{28)}$

Foaming slag, lower top gas flow rate and increasing lance height reduce the amount of spitting and splashing on the upper parts of the converter, thus skulling of the upper converter cone and converter mouth. As the angle of nozzles is reduced from $15^{\circ}$ to $12^{\circ}$, splashing and spitting increase significantly. This result agrees well with the findings by Keilman et al. ${ }^{26)}$ Patjoshi et al. ${ }^{29)}$ presented quite the contrary results to the present investigation.

\subsection{Experimental Apparatus}

A new cold model method for investigating splashing in the BOF was developed. The method enables quite fast determination of the effect of various parameters on the location and quantity of liquid splashed on the walls of the model. Furthermore, the scatter of results is very small according to the results.

Significant advantage to previously developed methods is that splashing is collected from the whole model wall circumference. This is of major importance when interaction between lance jet cavities and bottom blowing plumes results irregular splashing distribution on the walls.

The major limitations of this method are that neither thermal nor chemical similarity can be achieved. However, according e.g. Tanaka and Okane, ${ }^{5)}$ the direction of splashing is mostly dependent on the profile of a cavity, and according to Sharma et al. ${ }^{30)}$ the shape and depth of the cavity can be predicted from dynamically scaled water models. Furthermore, jet penetration is not affected by chemical reactions, the high temperature surroundings or interference with slag. ${ }^{30)}$ Later Kitamura and Okohira found out that decarburisation reaction has a clear effect on splash height. ${ }^{13)}$

\section{Conclusions}

The effect of various parameters on splashing behaviour in the BOF was studied. On the basis of this study, the following conclusions can be drawn.

(1) The taphole area exposes to severe splashing regardless of lance position or bottom gas flow rate.

(2) Although using lance angle of $12^{\circ}$ may improve the rate of decarburisation, according to the model tests

- the total amount of splashing and spitting increase considerably

- an increase in metal losses is expected

- skulling of the cone and converter mouth and consequently time for skull removal increases

- higher wear rate of the vessel bottom is likely

- reduced productivity

(3) Introduction of bottom blowing increases splashing significantly, especially on lower parts of the vessel. However, metal losses and skulling of the cone are simultaneously decreased.

(4) Lance position has an effect on total amount of splashing when bottom blowing is used. LP1 produces more severe areas of local stress than LP2 as well as slightly greater total splashing.

(5) The presence of even minor foam layer on water surface reduces the amount of total splashing significantly.

(6) Foamy slag, decreasing top gas flow rate and increasing lance height reduce metal losses and the skulling of the upper converter cone and converter mouth.

\section{Acknowledgements}

The project was funded by the National Technology Agency (Tekes) and Finnish steel industry. The authors are grateful to Olli Mattila for his valuable help. We would like to thank also Heikki Tenkku and Tapio Fabritius for their assistance.

\section{REFERENCES}

1) B. Deo and R. Boom: Fundamentals of Steelmaking Metallurgy, Prentice Hall International, London, (1993), 300.

2) N. A. Molloy: J. Iron Steel Inst., 206 (1970), 943.

3) A. Chatterjee and A. V. Bradshaw: J. Iron Steel Inst., 208 (1972), 179.

4) N. Standish and Q. L. He: ISIJ Int., 29 (1989), 455.

5) T. Tanaka and K. Okane: Tetsu-to-Hagané, 74 (1988), 1593.

6) A. Sakai, J. Tani, K. Yamada, K. Maya and S. Fukagawa: Steelmaking Conf. Proc., Vol. 77, ISS/AIME, Warrendale, PA, (1994), 61.

7) Y. Higuchi and Y. Tago: ISIJ Int., 41 (2001), 1454.

8) H-S. Choi, J-Y. Ryu, M. R. Kim, H. B. Lee, C. I. Kim and Y. H. Chung: Steelmaking Conf. Proc., Vol. 77, ISS/AIME, Warrendale, PA, (1994), 93.

9) G. Valentino, G. Mancano and A. De Cesare: 2nd European Oxygen Steelmaking Cong., Associazione Italiana Di Metallurgia, Milano, (1997), 79

10) Y. Tabata, R. C. Marsh, P. P. Kelly and T. Masaoka: 81st Steelmaking Conf. Proc., ISS, Warrendale, PA, (1998), 451.

11) J. M. Park and C. S. Ha: Rev. Métall., Cah. Inf. Tech., 97 (2000), 729.

12) S. Paul and D. N. Ghosh: Metall. Trans. B., 17B (1986), 461.

13) S-y. Kitamura and K. Okohira: Tetsu-to-Hagané, 76 (1990), 199.

14) A. P. Meshalkin, K. S. Prosvirin, V. B. Okhotskii and G. S. Kolganov: Steel USSR, 15 (1985), 369.

15) A. K. Garg and K. D. Peaslee: Iron Steelmaker, 25 (1998), No. 7, 57.

16) T. M. J. Fabritius, M. J. Luomala and J. J. Härkki: Ironmaking Steelmaking, 29 (2002), 29. 
17) M. J. Luomala, E. O. Virtanen, P. T. Mure, T. P. Siivola, T. M. J. Fabritius and J. J. Härkki: Steel Res., 73 (2002), 9.

18) Q. L. He and N. Standish: ISIJ Int., 30 (1990), 305.

19) K. D. Peaslee: Iron Steel Eng., 73 (1996), 33

20) S. C. Koria and K. W. Lange: Metall. Trans. B., 15B (1984), 109

21) S. C. Koria and K. W. Lange: Steel Res., 58 (1987), 421.

22) S. C. Koria and K. W. Lange: Arch. Eisenhüttenwes., 55 (1984), 427.

23) M-Y. Zhu, T. Inomoto, I. Sawada and T-C. Hsiao: ISIJ Int., 35 (1995), 472.

24) O. Haida and J. K. Brimacombe: SCANINJECT III, MEFOS, Luleå, (1983), 5: 1 .

25) J. K. Brimacombe, A. A. Bustos, D. Jorgensen and G. G. Richards:
Physical Chemistry of Extractive Metallurgy, Metall. Society/AIME, Warrendale, PA, (1985), 327.

26) L. M. Keilman, S. M. Galloway, S. R. Balajee and C. J. Bragg: 76th Steelmaking Conf. Proc., ISS, Warrendale, PA, (1993), 145.

27) L. Nedar: Steel Res., 67 (1996), 320.

28) M. Bock, J. Schoop and C. Oehler: 3rd European Oxygen Steelmaking Conf., Institute of Materials, London, (2000), 163.

29) A. K. Patjoshi, R. C. Behera, A. Sarangi and S. Misra: Iron Steel Int., 55 (1982), 27.

30) S. K. Sharma, J. W. Hlinka and D. W. Kern: Iron Steelmaker, 4 (1977) No. 7, 7. 